\title{
Tecnologias digitais nos currículos prescritos de Matemática no Brasil e em Portugal
}

\author{
Marcelo de Oliveira Dias ${ }^{1}$ \\ Leonor Santos ${ }^{2}$ \\ Jonei Cerqueira Barbosa ${ }^{3}$
}

\begin{abstract}
RESUMO
Este artigo apresenta uma análise comparativa de currículos prescritos recentes, referentes à utilização de tecnologias digitais na aprendizagem matemática no Brasil e em Portugal. Foram considerados os anos finais do ensino fundamental no Brasil, correspondendo em Portugal ao último ano do $2 .^{\circ}$ ciclo e todo o $3 .^{\circ}$ ciclo. A análise teve por base o quadro de referência do Projeto Matemática 2030 da OCDE. A tendência evidenciada na comparação dos currículos desses países se remete à ênfase na literacia digital, trazendo perspectivas aos estudantes para que utilizem aplicações interativas em processos que envolvem exploração, comunicação e representação. Foram constatadas ênfases precipitadas e reducionistas na abordagem ao pensamento computacional nos documentos de ambos os países. Suscita-se, portanto, a necessidade de reflexão dos responsáveis pela elaboração dos currículos e de novas pesquisas para sua inserção em futuras reformas dos Programas de Matemática desses países.
\end{abstract}

PALAVRAS-CHAVE: Investigação comparativa. Currículos prescritos de Matemática vigentes. Brasil e Portugal. Tecnologias digitais. Educação Matemática.

Digital technologies in prescribed mathematics curricula in Brazil

\footnotetext{
${ }^{1}$ Doutor em Educação Matemática. Universidade Federal Fluminense (UFF), Santo Antônio de Pádua, Rio de Janeiro, Brasil.: htts://orcid.org/0000-0002-3469-0041.marcelo_dias@id.uff.br.

2 Doutora em Educação.Universidade de Lisboa, Lisboa, Portugal. http://orcid.org/0000-0003-1283-032X. leonordsantos@sapo.pt.

${ }^{3}$ Doutor em Educação Matemática.Universidade Federal da Bahia (UFBA), Salvador, Brasil. http://orcid.org/00000002-4072-6442.joneicerqueira@gmail.com.
} 


\title{
and Portugal
}

\begin{abstract}
This article presents a comparative analysis of recent prescribed curricula, regarding the use of digital technologies in mathematical learning in Brazil and Portugal. The final years of elementary school in Brazil were considered, corresponding in Portugal to the last year of the 2nd cycle and the entire 3rd cycle. The analysis was based on the CEDO's 2030 Mathematical Project reference framework. The trend evidenced in the comparison of the curricula of these countries refers to the emphasis on digital literacy, bringing perspectives for students to use interactive applications in processes involving exploration, communication and representation. There were hasty and reductionist emphases in the approach to computational thinking in the documents of both countries. Therefore, there is a need for reflection by those responsible for preparing curricula and new research for their insertion in future reforms of the Mathematics Programs of these countries.
\end{abstract}

KEYWORDS: Comparative Investigation. Mathematics Prescribed Curricula In Use. Brazil and Portugal. Digital Technologies. Mathematical Education.

Tecnologías digitales en currículos de matemáticas prescritas en Brasil y Portugal

\section{RESUMEN}

Este artículo presenta un análisis comparativo de los planes de estudios reciente prescritos, sobre el uso de tecnologías digitales en el aprendizaje matemático en Brasil y Portugal. Se consideraron los últimos años de educación primaria en Brasil, correspondientes en Portugal al último año del segundo ciclo y todo el tercer ciclo. El análisis se basó en el marco de referencia del Proyecto matemático 2030 de la OCDE. La tendencia evidenciada en la comparación de los planes de estudio de estos países se refiere al énfasis en la alfabetización digital, brindando perspectivas para que los estudiantes usen aplicaciones interactivas en procesos que involucran exploración, comunicación y representación. Hubo énfasis apresurados y reduccionistas en el enfoque del pensamiento computacional en los documentos de ambos países. Por lo tanto, existe una 
necesidad de reflexión por parte de los responsables de preparar los planes de estudio y nuevas investigaciones para su inserción en futuras reformas de los Programas de Matemáticas de estos países.

PALABRAS CLAVE: Investigación comparativa. Plan de estudios de las matemáticas prescrito en vigor. Brasil y Portugal. Tecnologías digitales. Educación Matemática.

\section{Introdução}

Neste artigo, objetiva-se problematizar as recentes Reformas Educacionais no Brasil e em Portugal, em particular, em torno das questões: Quais as orientações dos documentos prescritos para a Matemática, vigentes nos dois países, no que respeita à utilização de tecnologias digitais (TD)? Que similaridades e especificidades existem entre os currículos prescritos? Essas questões foram problematizadas a partir do entendimento de que tais documentos enfatizam as TD numa tentativa de atender às demandas do mundo globalizado: alunos que se comunicam e resolvem situações e problemas matematicamente, nos quais os programas curriculares pretendem dar conta em seus percursos educacionais.

Assumimos a definição de currículo de Sacristán (2000, p. 34), que afirma ser um "projeto seletivo de cultura, cultural, social, política e administrativamente condicionado que preenche a atividade escolar e que se torna realidade dentro das condições da escola tal como se acha configurada". Esta escolha justifica-se pela diversidade de fatores envolvidos na elaboração e desenvolvimento dos currículos. Sobre o currículo prescrito, o autor diz que:

Em todo sistema educativo, como consequência das regulações inexoráveis às quais está submetido, levando em conta sua significação social, existe algum tipo de prescrição ou orientação do que deve ser seu conteúdo, principalmente em relação à escolaridade obrigatória. (SACRISTÁN, 2000, p. 104). 
Neste artigo, assumi-se essa definição de currículo para analisar como se configuram as TD e quais os desafios que as orientações curriculares em Matemática determinam tendo em conta os contextos educacionais do Brasil e de Portugal. Um primeiro fator passa pelo currículo escolar considerar ou não TD. Em caso afirmativo, duas situações poderão ser encontradas: $\mathrm{Ou}$ existe uma disciplina específica que as trabalha, ou correspondem a competências transversais a serem trabalhadas em diversas disciplinas. Deste modo, foca-se, primeiramente, nas competências gerais. Posteriormente, atende-se às recomendações específicas sobre TD presentes nos programas de Matemática dos dois países investigados.

A Base Nacional Comum Curricular (BNCC, 2017) no Brasil, ao prescrever uma das competências gerais que deve perpassar seus componentes, enuncia de forma clara a necessidade de uma cultura digital:

Utilizar tecnologias digitais de comunicação e informação de forma crítica, significativa, reflexiva e ética nas diversas práticas do cotidiano (incluindo as escolares) ao se comunicar, acessar e disseminar informações, produzir conhecimentos e resolver problemas. (BRASIL, 2017, p. 63).

Em Portugal, o Art. 6. ${ }^{\circ}$ do Diário da República, sobre a finalidade do currículo e sua promoção, estabelece princípios, valores e áreas de competência que devem obedecer ao desenvolvimento do currículo pensado para a globalização e o desenvolvimento tecnológico, visando preparar os alunos que serão jovens e adultos em 2030. Nele pode ler-se a importância de uma disciplina de TD:

Com vista a atingir aquela finalidade, e sem prejuízo da autonomia e flexibilidade exercida pela escola, à concepção do currículo subjazem os seguintes princípios. Promoção de aprendizagens no âmbito da disciplina de Tecnologias de Informação e Comunicação 
(TIC). (PORTUGAL, 2018, p. 2931).

Em Portugal as competências transversais a serem desenvolvidas deverão passar pela alfabetização em TIC: "Nos $2 .^{\circ}$ e $3 .^{\circ}$ ciclos, as matrizes curriculares-base integram a componente de Cidadania e Desenvolvimento e, em regra, a componente de TIC" (PORTUGAL, 2018, p. 2933).

No Brasil, o documento ao prescrever as TD refere-se à necessidade do uso de TIC de forma crítica e reflexiva para a construção de conhecimentos e resolução de problemas em variados contextos. Em Portugal, reconhece-se que capacidades em TICs no contexto da Autonomia e Flexibilização Curricular são contributivas para a promoção de aprendizagens.

Assim, as orientações curriculares em Matemática prescritas nos dois países, ao considerarem a importância da incorporação de TD em seus componentes, implicam para o desenvolvimento curricular em Matemática, uma particular atenção ao desenvolvimento de competências em Literacia Digital (LD) e no Pensamento Computacional (PC) para as novas gerações.

\section{Aspectos legais, processos e estrutura dos documentos para o Ensino}

\section{Fundamental}

A BNCC foi prevista na Constituição Federal para o Ensino Fundamental e ampliada no Plano Nacional de Educação (PNE) para o Ensino Médio, com o intuito de reelaborar e significar a educação básica no Brasil. A LDB, no Inciso IV de seu Art. 9. ${ }^{\circ}$, afirma que:

[...] cabe à União estabelecer, em colaboração com os Estados, o Distrito Federal e os Municípios, competências e diretrizes para a Educação Infantil, o Ensino Fundamental e o Ensino Médio, que nortearão os currículos e seus conteúdos mínimos, de modo a assegurar formação básica comum. (BRASIL, 1996 apud BRASIL, 2017, p. 10).

A partir desse inciso, a BNCC destaca como claros dois conceitos 
decisivos para todo o desenvolvimento da questão curricular no Brasil, baseados em duas noções consideradas como fundantes: o que é ou não básicocomum e as aprendizagens essenciais como foco:

O primeiro, já antecipado pela Constituição, estabelece a relação entre o que é básico-comum e o que é diverso em matéria curricular: as competências e diretrizes são comuns, os currículos são diversos. $\mathrm{O}$ segundo se refere ao foco. Ao dizer que os conteúdos curriculares estão a serviço do desenvolvimento de competências, orienta a definição das aprendizagens essenciais, e não apenas dos conteúdos mínimos a ser ensinados. (BRASIL, 2017, p. 11).

Para a sua elaboração, foram criadas equipes autônomas e um complexo processo de envio de sugestões para análise e promoção de debates estaduais. Em 2017, foi homologada a 3. ${ }^{a}$ versão (final) da BNCC para os Anos Iniciais e Finais do Ensino Fundamental, com ínicio de implementação no ano de 2019 .

A BNCC propõe cinco unidades temáticas, correlacionadas, que orientam a formulação de habilidades a serem desenvolvidas ao longo do Ensino Fundamental. Neste documento, competência é definida como a "mobilização de conhecimentos (conceitos e procedimentos), habilidades (práticas, cognitivas e socioemocionais), atitudes e valores para resolver demandas complexas da vida cotidiana, do pleno exercício da cidadania e do mundo do trabalho" (Brasil, 2017, p. 8). Nesse sentido, objetos de conhecimento e habilidades prescritas representam os pontos chaves da proposta para o desenvolvimento de competências matemáticas essenciais.

Em Portugal, segundo a Direção Geral de Educação (DGE), a última Revisão da Estrutura Curricular, legitimada no Decreto-lei n. ${ }^{\circ}$ 139/2012, de 5 de julho, bem como no Despacho n. ${ }^{\circ}$ 5306/2012, de 18 de abril, prevê melhoras da qualidade do ensino e da aprendizagem por meio de uma cultura de rigor e de excelência desde o Ensino Básico. Visando sua concretização, foram elaboradas as Metas Curriculares de Matemática (2012), onde estão 
elencados os objetivos gerais, especificados por descritores, de forma concisa que apontam para desempenhos precisos e avaliáveis.

Nas Metas Curriculares, “os conteúdos encontram-se organizados, em cada ciclo, por domínios. A articulação desejável entre os domínios de conteúdos e os objetivos antes enunciados encontra-se materializada" (MCMEB, 2012, p. 5). Assim, a DGE destaca que o Programa de Matemática do Ensino Básico (PMEB, 2013) foi construído com base nos conteúdos temáticos expressos no Programa de Matemática de 2007 (PMEB, 2007). Também destaca que a organização desses conteúdos numa hierarquia que se anuncia como coerente e consistente originou defasagens entre esse Programa e as Metas Curriculares, normativo legal e obrigatório.

Recentemente, as Orientações de Gestão Curricular para o Ensino Básico (2016) se configuraram como orientadores para a disciplina de Matemática, regendo-se pelo Programa e Metas Curriculares de Matemática para o Ensino Básico (PMCMEB, 2013). Estes introduzem orientações metodológicas gerais, bem como propostas de flexibilização e gestão de conteúdos, com indicações a serem equacionadas conforme o contexto.

Em 6 de julho de 2018 foi publicado no Diário da República, 1. ${ }^{\text {a }}$ série, n. 129, Art. 17, o documento curricular "Aprendizagens Essenciais (AE)", que:

Constituem orientação curricular de base, para efeitos de planificação, realização e avaliação do ensino e da aprendizagem, em cada ano de escolaridade ou de formação, componente de currículo, área disciplinar, disciplina (PORTUGAL, 2018, p. 2934).

Segundo a DGE, as AE constituirão o referencial base na planificação, realização e avaliação do ensino e aprendizagem, conducentes com competências do Perfil dos Alunos à saída da escolaridade obrigatória (PA). As AE foram construídos a partir de outros que se mantêm em vigor.

A DGE justifica a criação das AE pelo problema de extensão dos documentos curriculares, unanimemente reconhecido em Portugal. Assim, 
procurou identificar, disciplina a disciplina e ano a ano, o conjunto essencial de conteúdos, capacidades e atitudes, indispensáveis na aprendizagem. Este movimento, segundo a DGE, não traduziu revogação de programas em vigor, nem a consequente adoção de novos. As AE (2018) são o "Denominador Curricular Comum" para todos, constituindo-se, deste modo, como uma base comum de referência. Nas Figuras 1 e 2 são apresentadas as estruturas dos currículos prescritos para a Matemática no Brasil e em Portugal.

FIGURA 1: BNCC do Brasil (2017).
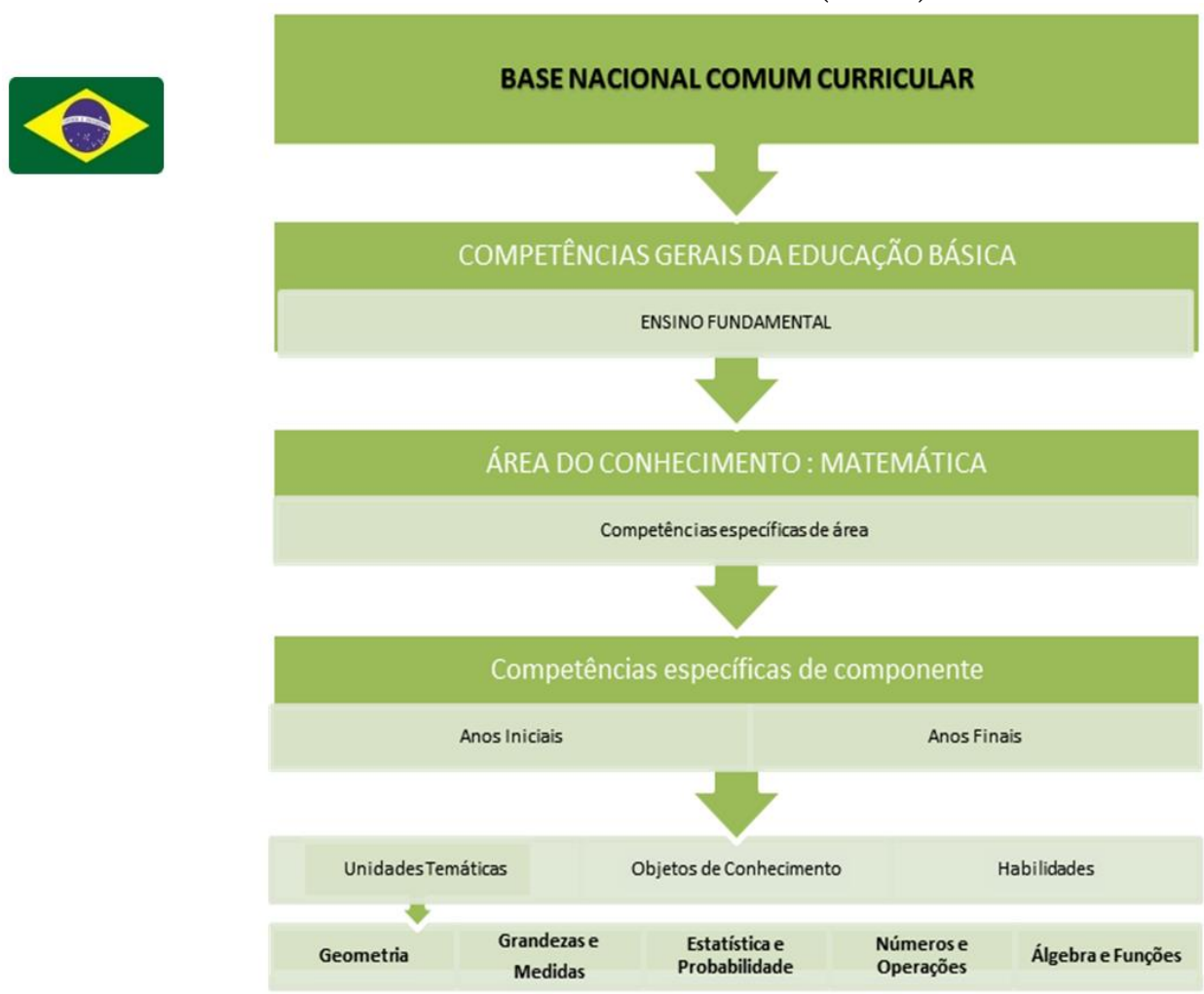

Fonte: Os autores a partir da BNCC (2017). 
FIGURA 2: Programa e Metas Curriculares de Matemática para o Ensino Básico (2013) e o documento Aprendizagens Essenciais (2018) de Portugal.

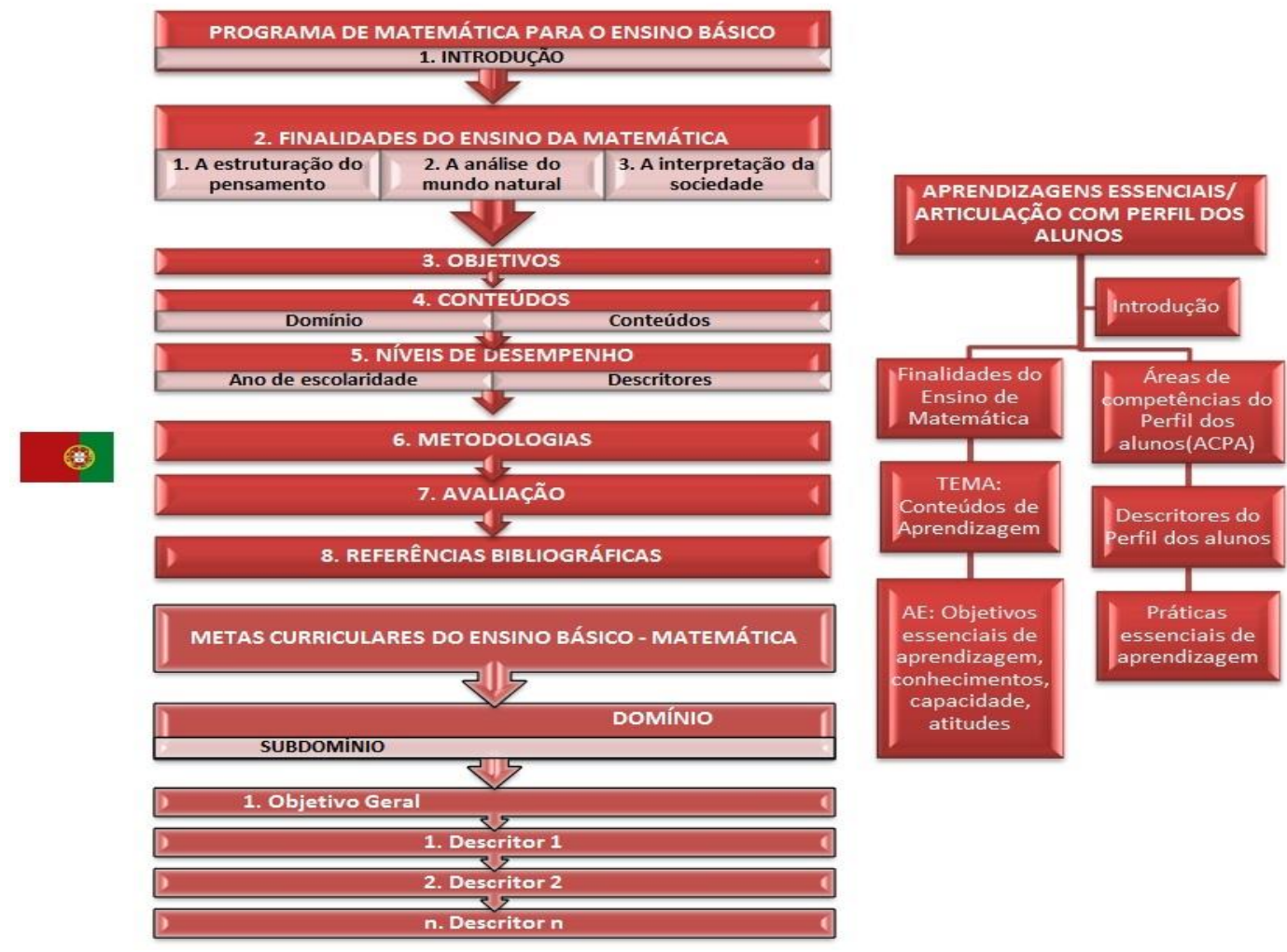

Fonte: Os autores a partir dos documentos PMCMEB (2013) e AE (2018).

Os documentos dos dois países apresentam estruturas bem específicas. A BNCC, documento prescrito no Brasil, apresenta enfatiza o encadeamento de competências gerais da etapa do Ensino Fundamental para a área de Matemática articulada com as competências específicas que se entrelaçam com as unidades temáticas, os objetos de conhecimento e suas habilidades.

Já em Portugal, a justaposição dos PMCMEB enfatizam as finalidades, objetivos, conteúdos, níveis de pensamento, metodologia, avaliação, domínios, subdomínios e os descritores. Similarmente, a estrutura do documento AE também enunciam domínios, subdomínios e descritores, porém com vistas a desenvolver a partir dos objetivos, conhecimentos, atitudes e capacidades em processos de práticas essenciais de aprendizagem.

\section{A tecnologia e os currículos prescritos de Matemática}

Referências relevantes para a discussão, como o documento para para 
o evento $24 .^{\circ}$ ICMI Study, fruto de discussões de pesquisadores renomados no âmbito internacional, apresentou como título "Reformas Curriculares na Matemática escolar: desafios, mudanças e oportunidades", ocorrido no Japão em 2018, destacou ser um imperativo fundamental para muitos países melhorarem as competências em Matemática dos estudantes que se tornarão agentes-chave nas sociedades em constante transformação, dada a internacionalização e globalização da economia e o avanço rápido da comunicação e outras TD.

Um dos temas do evento intitulado "Implementação de reformas dos currículos de Matemática dentro e em diferentes contextos e tradições”, trouxe questões como "Quais são os tipos de recursos e quais são os seus papéis (por exemplo, tecnologias) na reforma e implementação de currículos?" (ICMI Study, 2017, p. 11), remetendo-se ao papel das TD nas reformas.

O tema "Globalização, internacionalização e seus impactos sobre as reformas curriculares de Matemática", reforça que "estas influências parecem levar cada vez mais em direção a uma 'convergência' nas reformas dos currículos da Matemática. Semelhanças e especificidades podem ser observadas por meio de Estudos Comparativos" (ICMI Study, 2017, p. 12).

Essas influências internacionais envolvem organizações, como o Programa Internacional de Avaliação de Estudantes (PISA) e a Organização para a Cooperação e Desenvolvimento Econômico (OCDE). A título de exemplo, cita-se um estudo, desenvolvido por Kirwan e Hall (2015), que evidenciou que a reforma na Irlanda enfatizou o desenvolvimento sobre a tecnologia por sugestão da OCDE. Do mesmo modo, está em curso o Projeto Matemática 2030, que se propõe investigar até que ponto os países incorporam perspectivas amplas sobre Literacia Digital (LD) e habilidades do séc. XXI em seu atual currículo.

Martin (2006) define LD como a consciência, a atitude e a capacidade de utilizar soluções e facilidades digitais para identificar, acessar, gerenciar, integrar, avaliar, analisar e sintetizar recursos digitais, construir novos conhecimentos, criar expressões de mídia e se comunicar com os outros. As 
TD são relevantes na construção do conhecimento para que o aluno desenvolva competências de forma consciente e, além da sua usabilidade, saiba utilizá-las em seu cotidiano de forma crítica. (JENKINS et al., 2009).

As TD podem ser consideradas como estratégias para aprimorar a construção da aprendizagem Matemática (Dick e Hollebrans, 2011), contudo, a relação entre os conteúdos de Matemática e os de Computação estão ainda longe de serem idênticos (BARCELOS; SILVEIRA, 2012).

Apesar de haver indícios da transferência de competências entre os dois domínios, faz-se necessário um mapeamento no corpo de conhecimentos de ambas as áreas. A articulação entre PC e Matemática exige clara identificação dos momentos em que essa relação pode ocorrer ao longo do currículo escolar (BARCELOS; SILVEIRA, 2012).

Wing (2006) propôs competências sobre PC, como: Conceituar ao invés de programar; Habilidade fundamental e não utilitária; Complementa e combina a Matemática e Engenharia, ou seja, a "Matemática como base de inovação para crescimento econômico via Ciência, Tecnologia e Engenharia" (PISA, 2016, p. 4); Gera ideias e não artefatos; Para todos, em qualquer lugar.

A abordagem do PC na Educação Básica é importante por ser uma etapa que várias prioridades, ideologias e filosofias lutam por atenção (Barcelos, Munõz, Villarroel e Silveira, 2015; CSTA, 2011).

Os resultados dos estudos apresentados reforçam a necessidade de comparação e a adoção de categorias referentes às perspectivas e desafios sobre a LD e o PC nas prescrições curriculares para o ensino de Matemática das gerações atual e futura de jovens brasileiros e portugueses, destacando a necessidade de reflexão crítica, escolhas adequadas para a exploração e dinamização além dos conteúdos, tomada de decisões, competências entre dois domínios. Nesse sentido, a partir de reformas recentes nos programas prescritos, propôs-se realizar um estudo comparativo concernente às recomendações nestes documentos sobre a utilização de TD.

\section{Método comparativo}

Ferrer (2002) destaca quatro finalidades da Educação Comparada: (a) 
ilustrar as diferenças ou semelhanças entre os sistemas de educação dos países; (b) mostrar a importância dos fatores contextuais dos sistemas educativos como elementos explicativos de si mesmo; (c) estabelecer as possíveis influências que têm os sistemas educativos sobre determinados fatores contextuais; e (d) contribuir para melhor compreender o próprio sistema mediante os sistemas educativos de outros países.

O estudo foi desenvolvido nas fases propostas por Ferrer (2002): (1. $\left.{ }^{a}\right)$ Fase pré-descritiva - seleção, identificação e justificativa do problema; formulação de hipóteses; delimitação da investigação; (2. $\left.{ }^{a}\right)$ Fase descritiva - apresentação dos dados contextuais, caracterizando o sistema educacional; $\left(3 .^{a}\right)$ Fase interpretativa - interpretação dos dados da fase anterior, finalizando com uma síntese analítica com conclusões; (4. ${ }^{a}$ ) Fase de justaposição - confrontação dos dados produzidos nas fases anteriores; $\left(5 .^{a}\right)$ Fase comparativa - discussão das hipóteses a partir dos dados apresentados nas fases anteriores, bem como a discussão das questões de pesquisa; e (6. ${ }^{a}$ ) Fase prospectiva (optativa) - indicação de tendências em Educação nos países estudados.

A pesquisa foi constituída de uma análise documental dos currículos prescritos de Matemática dos dois países que, segundo Sharma (2013), se configura como:

Uma forma de coletar informações qualitativas de uma fonte primária ou original de materiais escritos, impressos e gravados para responder às perguntas de pesquisa em estudos de caso interpretativos. Os documentos fornecem evidências de atividades autênticas ou reais realizadas em organizações sociais e de pensamento humano (SHARMA, 2013, p. 3).

Planejou-se, então, uma pesquisa documental, procurando, nos documentos curriculares oficiais vigentes para o Ensino Básico (Quadro 1), uma organização sobre quais recomendações acerca do uso de TD apresentam para a Matemática no Brasil e em Portugal. Para tal, foi considerado como 
critério de comparação as orientações curriculares prescritas sobre TD somente em unidades comuns nos documentos em vigor nos dois países, uma vez que são de anos escolares correspondentes, de forma que a comparação fosse adequada.

QUADRO 1: Documentos analisados para o Ensino Básico do Brasil e de Portugal.

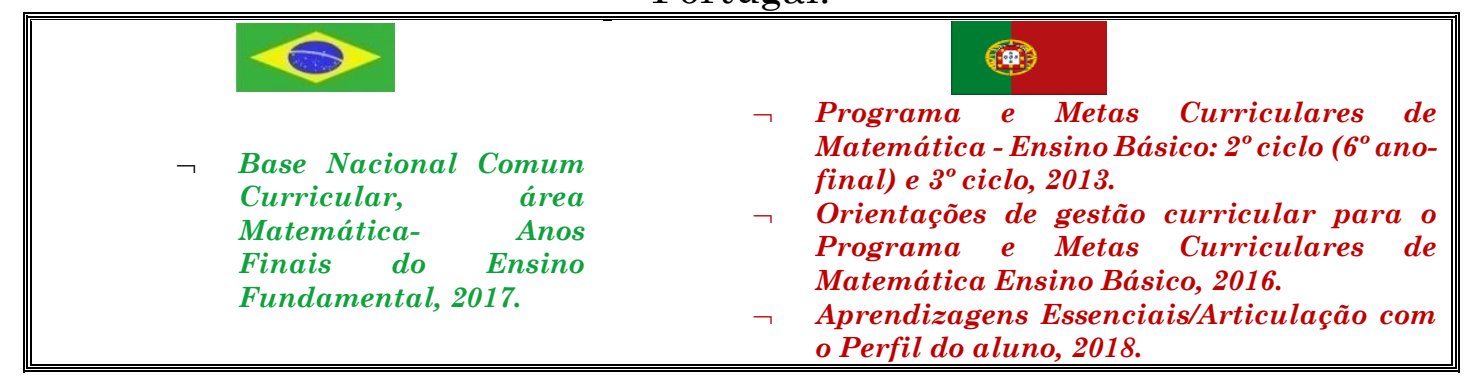

Fonte: Os autores.

Foram realizadas inicialmente uma pré-análise dos documentos curriculares vigentes e suas intencionalidades, de discursos da Sociedade Brasileira de Computação (SBC, 2018), que emitiu notas sobre a BNCC no Brasil, e pela $1^{a}$ versão do documento emitido pelo Grupo de Trabalho de Matemática (GTM, 2019), ao qual foi atribuída a missão de elaborar um conjunto de recomendações sobre o ensino, a aprendizagem e a avaliação na disciplina de Matemática em Portugal, visando caracterizar tendências expressas nas reformas curriculares que vêm sendo realizadas nesses países e nortear o ensino de gerações futuras.

O Projeto Matemática 2030, desenvolvido pela OCDE, visa auxiliar os países a identificar os conhecimentos, habilidades, atitudes e valores que serão necessários para que os estudantes possam prosperar e moldar seu mundo, bem como modos dos sistemas educativos poderem efetivamente desenvolvê-los, numa nova realidade:

[...] tecnologias que ainda não foram inventadas, e resolver problemas sociais que ainda não tenham sido antecipados. A educação pode equipar os alunos com a agência, as competências e sentido de propósito para moldar suas próprias vidas e contribuir 
para as dos outros. Assim sendo, a mudança é iminente. (OCDE, 2018, p. 1)

O Projeto também pretende conceder suporte aos países na abordagem de desafios comuns à implementação de currículos e na identificação de fatores críticos de sucesso. A vertente 1 do projeto refere-se à elaboração de um quadro de aprendizagem para a Matemática 2030, e a vertente 2, na Análise de Programas Curriculares Internacionais, visando construir uma base de conhecimento que permitirá aos países tornarem os processos de design de currículo mais sistemáticos. Isto significa apoiar a aprendizagem entre pares internacionais e debates entre as partes interessadas.

Assim, as categorias de análise do presente estudo foram inspiradas no quadro de análise do Projeto Matemática 2030 (Quadro 2), definidas na versão não definitiva da vertente 1 do Projeto, com o intuito de destacar as similaridades e especificidades nas prescrições dos dois países.

QUADRO 2: Quadro de aprendizagem do Projeto Matemática 2030.

\begin{tabular}{|c|c|}
\hline $\begin{array}{c}\text { CATEGORIA C1: } \\
\text { Alfabetização em } \\
\text { TIC/ Literacia } \\
\text { Digital }\end{array}$ & $\begin{array}{l}\text { As Tecnologias da Informação e Comunicação (TIC) são definidas como } \\
\text { todos os componentes relacionados a TD e computadores. O termo TIC } \\
\text { refere-se a todos os dispositivos, componentes de rede, aplicativos e } \\
\text { sistemas que permitam que pessoas e organizações interajam no mundo } \\
\text { digital. Os alunos alfabetizados digitais têm o conhecimento, a } \\
\text { compreensão, as habilidades e as disposições para usar os equipamentos } \\
\text { digitais de maneira eficaz e apropriada na escola e para além da escola. } \\
\text { Alunos com essa capacidade são capazes de fornecer, criar e comunicar } \\
\text { informações e conceitos. Eles são capazes de se adaptar às mudanças } \\
\text { tecnológicas e usar tecnologias para alcançar um propósito e se comunicar } \\
\text { com os outros usando esses equipamentos. }\end{array}$ \\
\hline $\begin{array}{c}\text { CATEGORIA C2: } \\
\text { Pensamento } \\
\text { computacional/ } \\
\text { programação/codifi } \\
\text { cação }\end{array}$ & $\begin{array}{l}\text { O pensamento computacional envolve a formulação de problemas e o } \\
\text { desenvolvimento de soluções que podem ser realizadas por tecnologias } \\
\text { baseadas em computador. Programação e codificação envolvem o } \\
\text { desenvolvimento de conhecimento, compreensão e habilidades em relação } \\
\text { à linguagem, padrões, processos e sistemas necessários para } \\
\text { instruir/direcionar dispositivos como computadores e robôs. }\end{array}$ \\
\hline
\end{tabular}

Fonte: OCDE - Documento Preliminar (2018, p. 9).

O quadro de aprendizagem apresenta fundamentos para 0 desenvolvimento de competências consideradas relevantes para as gerações futuras no que tange a utilização de TD.

\section{Apresentação dos dados}




\section{Fase pré-descritiva}

Primeiramente, debruçou-se na "Apresentação" dos documentos prescritos considerados para análises referentes aos Anos Finais do Ensino Fundamental no Brasil e em Portugal, ano final do $2 .^{\circ}$ ciclo e todo o $3 .^{\circ}$ ciclo.

A análise pré-descritiva permitiu inferir que a comparação ano a ano tornou-se possível considerando somente a BNCC no Brasil e as AE em Portugal, visto que os PMCMEB e o documento de orientação para a sua gestão, não apresentam prescrições específicas referentes à utilização de TD concomitantes nos anos investigados.

\section{Fase descritiva e interpretativa \\ $6 .^{\circ}$ ano}

No 6. ${ }^{\circ}$ ano, o primeiro dos Anos Finais do Ensino Fundamental no Brasil e o último do $2 .^{\circ}$ ciclo em Portugal, encontram-se recomendações curriculares sobre a utilização das TD nos documentos prescritos na unidade "Geometria".

A BNCC prescreve as seguinte habilidades, como mostrado na Fig. 10:

FIGURA 3: BNCC para a unidade Geometria no $6 .^{\circ}$ ano.

\begin{tabular}{|c|c|}
\hline $\begin{array}{l}\text { Construção de } \quad \text { figuras } \\
\text { semelhantes: ampliação e redução } \\
\text { de figuras planas em malhas } \\
\text { quadriculadas. }\end{array}$ & $\begin{array}{l}\text { (EFO6MA21) Construir figuras planas semelhantes em } \\
\text { situações de ampliação e de redução, com o uso de malhas } \\
\text { quadriculadas, plano cartesiano ou tecnologias digitais (Brasil, } \\
2017, \text { p. 301). }\end{array}$ \\
\hline $\begin{array}{l}\text { Construção de retas paralelas e } \\
\text { perpendiculares, fazendo uso de } \\
\text { réguas, esquadros e softwares. }\end{array}$ & $\begin{array}{l}\text { (EF06MA22) Utilizar instrumentos, como réguas e esquadros, } \\
\text { ou softwares para representações de retas paralelas e } \\
\text { perpendiculares e construção de quadriláteros, entre outros } \\
\text { (Brasil, 2017, p. 301). }\end{array}$ \\
\hline
\end{tabular}

Fonte: Brasil (2017).

Para o objeto "Construção de figuras semelhantes" na BNCC, as TD são apontadas, com outros recursos, como uma das possibilidades de construção e interação para promover a ampliação e redução de figuras. Para o objeto “Construção de retas paralelas e perpendiculares", sugere a utilização de software para situações de representação, construção, dentre outras.

No que tange o PC, conforme a Fig. 11, a BNCC recomenda: 
FIGURA 4: Habilidade questionada pela SBC para o $6 .^{\circ}$ ano.

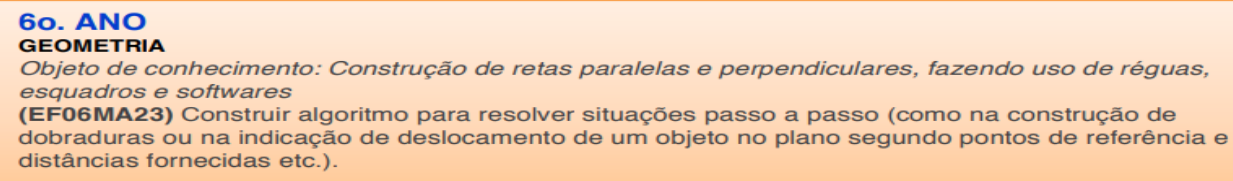

Fonte: SBC (2018, p. 4)

A SBC (2018) questionou a relação da habilidade com o objeto de conhecimento supracitado, reforçando que a palavra software não possui plural. Infere-se, também, que a construção de algoritmos para resolver situações passo a passo remete-se a um engessamento de resolução linear e pouco crítica em termos de apropriações conceituais.

Em Portugal, as AE para "Geometria e Medida” preveem que deverão ser criadas condições para experiências individuais e em grupo, usando TD para construção de modelos geométricos em conteúdos que envolvam a exploração de propriedades de Geometria Plana e Espacial, por meio de aplicações interativas, programas computacionais e calculadora (Fig. 12).

FIGURA 5: AE (2018) para o tema "Geometria e Medida" no $6^{\circ}$ ano.

- Utilizar modelos geométricos e outros materiais manipuláveis, e instrumentos variados
incluindo os de tecnologia digital, nomeadamente aplicações interactivas, programas
computacionais específicos e calculadora, na exploração de propriedades de figuras planas e de
sólidos geométricos (Portugal, 2018, p. 11).

Fonte: Portugal (2018, p. 11).

As AE sugerem a utilização de TD em Geometria Espacial e recomendam a calculadora, recursos e programas específicos em situações de exploração de propriedades de figuras planas e de sólidos.

\section{7. ${ }^{\circ}$ ano}

$\mathrm{Na}$ unidade "Geometria" na BNCC para o 7. ano, são prescritas as habilidades mostradas na Fig. 13. 
FIGURA 6: BNCC para a unidade "Geometria" para o $7 .^{\circ}$ ano.

\begin{tabular}{|l|l|l|}
\hline $\begin{array}{l}\text { Simetrias de translação, rotação } \\
\text { e reflexão }\end{array}$ & $\begin{array}{l}\text { EFO7MA21) Reconhecer e construir figuras obtidas por simetrias } \\
\text { de translação, rotação e reflexão, usando instrumentos de desenho } \\
\text { ou softwares de geometria dinâmica e vincular esse estudo a } \\
\text { representações planas de obras de arte, elementos arquitetônicos, } \\
\text { entre outros (Brasil, 2017,p. 307). }\end{array}$ \\
\hline $\begin{array}{l}\text { Relações entre os ângulos } \\
\text { formados por retas paralelas } \\
\text { intersectadas por uma transversal }\end{array}$ & $\begin{array}{l}\text { EF07MA23) Verificar relações entre os ângulos formados por } \\
\text { retas paralelas cortadas por uma transversal, com e sem uso de } \\
\text { softwares de geometria dinâmica (Brasil, 2017, p. 307). }\end{array}$ \\
\hline
\end{tabular}

Fonte: Brasil (2017).

Para o reconhecimento e construção de figuras por meio de isometrias simples (simetria, rotação e reflexão), a BNCC prevê o recurso a software de geometria dinâmica, associando-as a representações planas de obras de arte.

Referente ao objeto "Relações entre os ângulos formados por retas paralelas intersectadas por uma transversal", o documento prescreve que os alunos deverão verificar a relação entre ângulos, recorrendo também a software de geometria dinâmica.

Para o desenvolvimento do PC, a BNCC para $7^{\circ}$ ano prescreve as seguintes habilidades ilustradas na Fig. 14 abaixo:

FIGURA 7: Habilidades questionadas pela SBC para o $7 .^{\circ}$ ano.

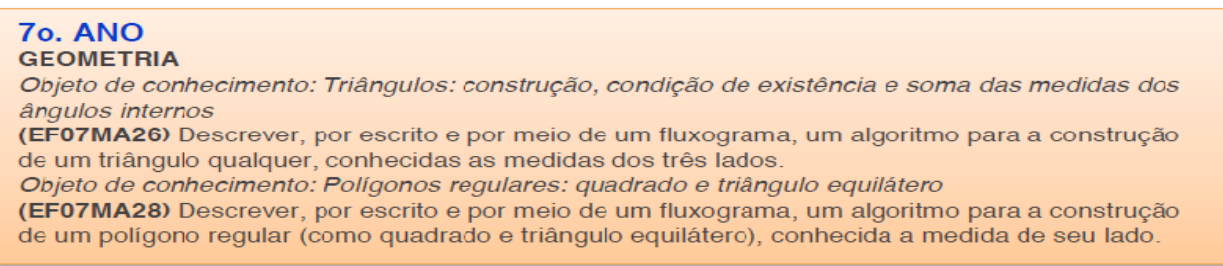

Fonte: SBC (2018, p. 5).

A SBC (2018) questionou o fato de a habilidade ser extremamente específica na perspectiva da construção de um algoritmo concreto, e que as habilidades deveriam ser mais genéricas, sinalizando novamente que os fluxogramas não deveriam ser requeridos nessa recomendação.

No primeiro ano do $3 .^{\circ}$ ciclo, para o tema "Geometria e Medidas", as AE referem-se ao uso variado das TD e também à atividades que requeiram resolução de problemas, raciocínio e comunicação matemática, para que os alunos sejam capazes de, segundo a Fig. 15: 
FIGURA 8: AE para o tema "Geometria e Medidas" no 7. ${ }^{\circ}$ ano.

\begin{tabular}{l} 
- Construir quadriláteros a partir de condições dadas e recorrendo a instrumentos apropriados, \\
incluindo os de tecnologia digital (Portugal, 2018, p. 9). \\
\hline - Identificar e representar semelhanças de figuras no plano, usando material e instrumentos \\
apropriados, incluindo os de tecnologia digital, e utilizá-las em contextos matemáticos e não \\
matemáticos, prevendo e descrevendo os resultados obtidos, incluindo o seu efeito em \\
comprimentos e áreas (Portugal, 2018, p. 9). \\
- Resolver problemas usando ideias geométricas em contextos matemáticos e não matemáticos, \\
concebendo e aplicando estratégias de resolução, incluindo a utilização de tecnologia, e \\
avaliando a plausibilidade dos resultados (Portugal, 2018, p. 9). \\
\hline
\end{tabular}

Fonte: Portugal (2018).

As AE prescrevem as TD em situações que devam ser incluídas em conhecimentos relativos à construção de quadriláteros e ao trabalho com figuras semelhantes no plano. Também, à resolução de problemas que envolvam ideias geométricas em contextos matemáticos e não matemáticos. Recomenda, ainda (Fig. 16):

FIGURA 9: AE para o tema "Geometria e Medidas" no 7. ano.

- Utilizar modelos geométricos e outros materiais manipuláveis, e instrumentos variados, incluindo os de tecnologia digital e a calculadora (Portugal, 2018, p. 9).

Fonte: Portugal (2018).

As AE preveêm como "Práticas Essenciais de Aprendizagem" aquelas em que os alunos incluam as TD e a calculadora para a utilização de modelos geométricos e outros instrumentos para a abordagem do tema referido.

\section{8. ${ }^{\circ}$ ano}

A BNCC, na unidade "Geometria", prescreve as habilidades da Fig. 17:

FIGURA 10: BNCC para a unidade "Geometria" no $8 .^{\circ}$ ano.

\begin{tabular}{|l|l|}
\hline $\begin{array}{l}\text { Construções geométricas: } \\
\text { ângulos de } 90^{\circ}, 60^{\circ}, 45^{\circ} \text { e } 30^{\circ} \\
\text { e polígonos regulares. }\end{array}$ & $\begin{array}{l}\text { (EFO8MA15) Construir, utilizando instrumentos de desenho ou } \\
\text { softwares de geometria dinâmica, mediatriz, bissetriz, ângulos de } \\
90^{\circ}, 60^{\circ}, 45^{\circ} \text { e } 30^{\circ} \text { e polígonos regulares (Brasil, 2017, p. 313). }\end{array}$ \\
\hline $\begin{array}{l}\text { Transformações geométricas: } \\
\text { simetrias de translação, } \\
\text { reflexão e rotação. }\end{array}$ & $\begin{array}{l}\text { (EFO8MA18) Reconhecer e construir figuras obtidas por } \\
\text { composições de transformações geométricas (translação, reflexão } \\
\text { e rotação, com o uso de instrumentos de desenho ou de softwares } \\
\text { de geometria dinâmica (Brasil, 2017, p. 313). }\end{array}$ \\
\hline
\end{tabular}

Fonte: Brasil (2017).

Para o $8 .^{\circ}$ ano, a BNCC enfatiza a construção de ângulos e polígonos regulares e isometrias por meio de instrumentos de desenho ou software.

Sobre o desenvolvimento do $\mathrm{PC}$, a $\mathrm{BNCC}$ recomenda o desenvolvimento 
da habilidade mostrada na Fig. 18:

FIGURA 11: Habilidade questionada pela SBC (2018) para a Geometria.

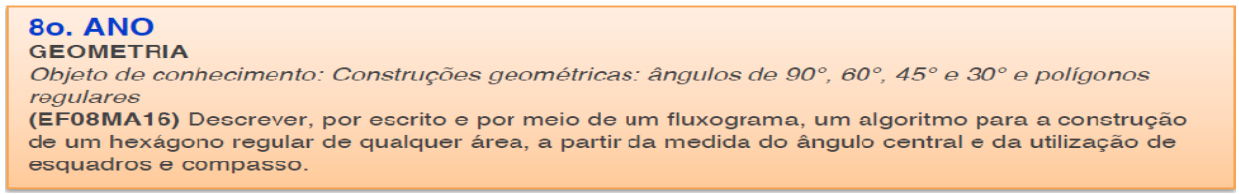

Fonte: (SBC, 2018, p. 5).

A SBC (2018) questionou o porquê da concretude do algoritmo e da utilização específica do fluxograma e infere que essas habilidades deveriam ser mais genéricas.

Para o tema "Geometria e Medidas", as AE prescrevem que os alunos deverão, como mostrado na Fig. 19, ser capazes de:

FIGURA 12: AE para o tema "Geometria e Medidas" no 8. ano.

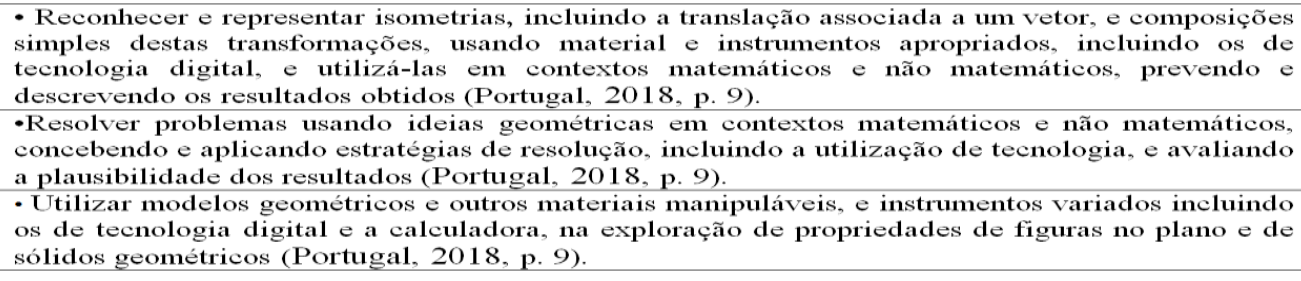

Fonte: Portugal (2018).

As AE enfatizam as TD como instrumentos necessários para previsão, reconhecimento, representação e descrição das isometrias e outras ideias.

Para a unidade "Números", a BNCC prescreve o apresentado na Fig. 20:

FIGURA 13: BNCC para a unidade "Números" no $8 .^{\circ}$ ano. Porcentagens $($ EF08MA04) Resolver e elaborar problemas, envolvendo cálculo de Porcentagens $\begin{aligned} & \text { (EFO8MA04) Resolver e elaborar problemas, envolvendo cálculo } \\ & \text { porcentagens, incluindo o uso de tecnologias digitais (BNCC, 2017, p. 311). }\end{aligned}$

Fonte: Brasil (2017).

A BNCC salienta que, para desenvolver a capacidade de resolver e elaborar problemas com porcentagens, os alunos deverão recorrer às TD.

Em Portugal, as AE para "Números e Operações" sugerem que (Fig. 21): 
FIGURA 14: AE para o tema "Números e Operações" no $8 .^{\circ}$ ano. - Resolver problemas com números racionais em contextos matemáticos e não matemáticos, concebendo e aplicando estratégias de resolução, incluindo a utilização de tecnologia, e avaliando a plausibilidade dos resultados (Portugal, 2018, p. 7).

Fonte: Portugal (2018).

O documento também indica, na sessão "Práticas Essenciais de Aprendizagem", que devem ser criadas condições em experiências individuais e de grupo para que os alunos tenham oportunidade de, conforme Fig. 22:

FIGURA 15: AE para o tema "Números e Operações" no 8. ano.

- Utilizar materiais manipuláveis e outros recursos, incluindo os de tecnologia digital, na resolução de problemas e em outras tarefas de aprendizagem (Portugal, 2018, p. 7)

Fonte: Portugal (2018).

As AE recomendam que os alunos deverão incluir as TD e os demais recursos como estratégia de resolução de problemas com números racionais em contextos variados.

Mostrar a relação entre números racionais na forma decimal e os valores financeiros entre as grandezas, além de outras, poderão ser foco em atividades que envolvam unidades de medida. As TD permitem simular e/ou testar conjecturas sobre números racionais. Esse cenário de potencialidades permite experimentações para um processo de aprendizagem com precisão de detalhes nas representações.

Finalmente, a BNCC traz a seguinte perspectiva em "Álgebra" (Fig. 23):

FIGURA 16: BNCC para a unidade "Álgebra" no $8 .^{\circ}$ ano. \begin{tabular}{|l|l|}
\hline $\begin{array}{l}\text { Equação polinomial } \\
\text { de } 2^{\circ} \text { grau do tipo } \\
a^{2}=b\end{array}$ & $\begin{array}{l}\text { (EFO8MA09) Resolver e elaborar, com e sem uso de tecnologias, } \\
\text { problemas que possam ser representados por equaçoses polinomiais de } 2^{\circ} \\
\text { grau do tipo ax }{ }^{2}=\text { b (Brasil, 2017, p. 311). }\end{array}$ \\
\hline
\end{tabular}

Fonte: Brasil (2017).

A BNCC prevê que os alunos deverão elaborar e resolver problemas que possam ser representados por equações polinomiais de grau dois, incluindo procedimentos com ou sem TD. Perspectivas de trabalho sobre o PC foram indicadas para o $8^{\circ}$ ano nas habilidades apresentadas na Fig. 24 a seguir: 
FIGURA 17: Habilidades da BNCC sobre PC para o $8 .^{\circ}$ ano.

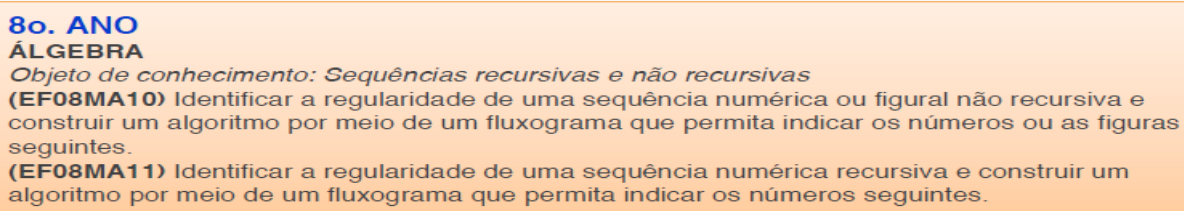

Fonte: SBC (2018, p. 5).

Para a unidade "Álgebra", além de reforçar sua crítica à utilização de fluxogramas, a SBC (2018, p. 5) faz o seguinte alerta:

Uma sequência recursiva é uma sequência que tem uma Lei de formação. Consequentemente, não é possível construir um algoritmo para determinar o próximo número de uma sequência não recursiva, como sugere a habilidade EF08MA10 (pois ela não tem lei de formação, só é possível construir algoritmos para processos que têm lei de formação).

Para "Álgebra", as AE recomendam a criação de condições para (Fig. 25):

FIGURA 18: AE para o tema "Álgebra" no 8. ${ }^{\circ}$ ano.

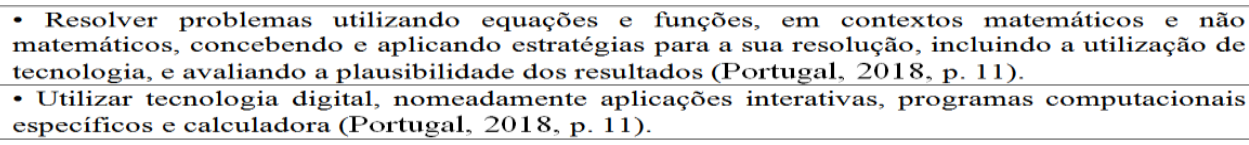

Fonte: Portugal (2018).

As AE prescrevem para a resolução de problemas com conceitos de equações e funções sejam incluídas TD como estratégia de resolução e avaliação dos resultados. No entanto, o recente relatório do estudo realizado pelo GTM (2019), problematiza tal abordagem:

Apesar de as práticas essenciais se referirem ao uso da tecnologia digital, em nenhuma passagem fica claro se a resolução das equações pode ou não ser realizada com recurso a tecnologia e que 
papel esta assume. Será muito diferente usar a tecnologia para comprovar as resoluções algébricas e comparar com as representações gráficas feitas à mão ou usar a tecnologia como geradora de soluções a selecionar com critérios e como banco de experiência que apoiam conjeturas. Assim, as AE revelam também dificuldades na definição clara da sua abordagem à Matemática (GTM, 2019, p. 63).

As $\mathrm{AE}$ referem-se especificamente à capacidade de resolver problemas em variados contextos e conceber e aplicar estratégias recorrendo às TD, porém sem uma clara definição desse uso e do seu objetivo.

\section{9. ${ }^{\circ}$ ano}

Finalmente, para a unidade "Geometria", a BNCC faz menção às tecnologias, como mostrado na Fig. 26.

FIGURA 19: BNCC para a unidade "Geometria" no 9. ano.

\begin{tabular}{|l|l|}
\hline $\begin{array}{l}\text { Relações entre arcos ângulos na na } \\
\text { e afo9MA11) Resolver problemas por meio do estabelecimento de relações } \\
\text { circunferência de um } \\
\text { círculo }\end{array}$ & $\begin{array}{l}\text { (EFôa } \\
\text { entre arcos, ângulos centrais e ângulos inscritos na circunferência, fazendo } \\
\text { uso, inclusive, de softwares de geometria dinâmica (Brasil, 2017, p. 315). }\end{array}$ \\
\hline Polígonos regulares & $\begin{array}{l}\text { (EFO9MA15) Descrever, por escrito e por meio de um fluxograma, um } \\
\text { algoritmo para a construção de um polígono regular cuja medida do lado é } \\
\text { conhecida, utilizando régua e compasso, como também softwares (Brasil, } \\
2017, \text { p. 317). }\end{array}$ \\
\hline
\end{tabular}

Fonte: Brasil (2017).

A ênfase dada pela BNCC é que os estudantes desenvolvam habilidades para resolver problemas e estabelecer relações entre arcos e ângulos na circunferência de um círculo, incluindo procedimentos com software de geometria dinâmica. Além disso, descrevam por extenso e estruturem fluxogramas para a construção de polígonos regulares, utilizando régua e compasso. A BNCC apresenta, ainda, a habilidade expressa na Fig. 27.

FIGURA 20: Habilidades sobre PC para o $9 .^{\circ}$ ano.

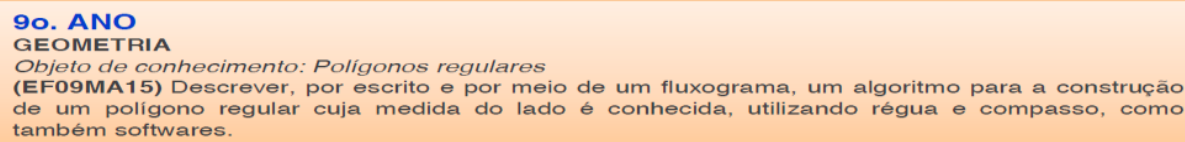

Fonte: SBC (2018, p. 6). 
Novamente a crítica recai da SBC (2018) sobre a ênfase nos fluxogramas, nos algoritmos concretos e na prescrição da palavra software no plural.

Em "Geometria e Medidas", as AE pressupõem (Fig. 28):

Figura 21: AE para o tema "Geometria e Medidas" no 9. ano. - Utilizar modelos geométricos e outros materiais manipuláveis, e instrumentos variados, incluindo os de tecnologia digital e a calculadora (Portugal, 2018, p. 9).

- Resolver problemas usando ideias geométricas em contextos matemáticos e não matemáticos concebendo e aplicando estratégias de resolução, incluindo a utilização de

tecnologia, e avaliando a plausibilidade dos resultados (Portugal, 2018, p. 11).

Fonte: Portugal (2018).

A ênfase dada pelas AE é que estudantes deverão resolver problemas com a utilização de ideias geométricas, incluindo a tecnologia (digital ou não digital), para verificação de resultados.

Para o 9. ${ }^{\circ}$ ano, a BNCC para a unidade "Números", traz a seguinte prescrição (Fig. 29):

FIGURA 22: BNCC para a unidade Números no $9^{\circ}$ ano.

\begin{tabular}{|l|l|}
\hline $\begin{array}{l}\text { Porcentagens: problemas } \\
\text { que envolvem cálculo de } \\
\text { percentuais sucessivos }\end{array}$ & $\begin{array}{l}\text { (EF09MA05) Resolver e elaborar problemas que envolvam } \\
\text { porcentagens, com a ideia de aplicação de percentuais sucessivos e } \\
\text { a determinação das taxas percentuais, preferencialmente com o uso } \\
\text { de tecnologias digitais, no contexto da educação financeira (Brasil, } \\
2017, \text { p.315). }\end{array}$ \\
\hline
\end{tabular}

Fonte: Brasil (2017).

$\mathrm{Na}$ unidade "Números", a BNCC enfatiza para o trabalho com "Porcentagens", que os alunos deverão resolver e elaborar problemas com percentuais sucessivos e determinação de taxas, preferencialmente, com o uso de TD, em situações de educação financeira.

Em Portugal, foram destacadas perspectivas relacionadas com o uso de TD para o tema "Números e Operações", conforme a Fig. 30 a seguir:

FIGURA 23: AE para o tema "Números e Operações" no 9. ${ }^{\circ}$ ano.

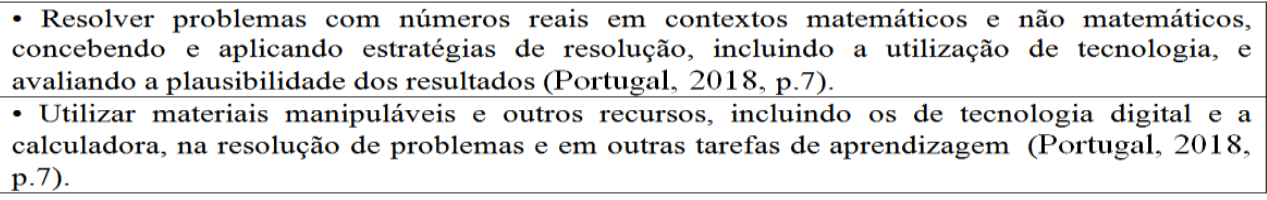

Fonte: Portugal (2018). 
As AE sinalizam que os alunos deverão resolver problemas com números reais em vários contextos, concebendo e aplicando estratégias com a utilização de TD. A calculadora e as TD são enfatizadas como imprescindíveis em aplicações de estratégias e na verificação das soluções.

\section{Fases de Justaposição, Comparativa e de Prospecção}

Esta sessão destina-se à síntese das fases de justaposição e comparativa, buscando, a partir dos dados apresentados nas fases anteriores, destacar as similaridades e especificidades, com o intuito de realizar uma prospeç̧ão com o intuito de apontar tendências em Educação Matemática nos documentos curriculares vigentes no Brasil e em Portugal no que tange às prescrições sobre a recursão às TD.

QUADRO 3: Similaridades e especificidades referentes à utilização de TD nos documentos curriculares do Brasil e de Portugal.

\begin{tabular}{|c|c|c|c|c|}
\hline \multirow[b]{2}{*}{ ANO } & \multirow[b]{2}{*}{ UNIDADE } & SIMILARIDADES & \multicolumn{2}{|c|}{ ESPECIFICIDADES } \\
\hline & & $\bigoplus_{\text {BNCC/AE }}$ & BNCC & $\mathrm{AE}$ \\
\hline $6^{\circ}$ & Geometria & $\begin{array}{llr}\text { Recomendam utilizar as TD } \\
\text { por meio de } & \text { aplicações } \\
\text { interativas } & \text { com } & \text { software } \\
\text { específicos em } & \text { Geometria } \\
\text { Plana. } & & \end{array}$ & $\begin{array}{l}\text { Recomenda a construção de } \\
\text { figuras semelhantes e planas e } \\
\text { de retas paralelas e } \\
\text { perpendiculares por meio de } \\
\text { software. } \\
\text { A construção de algoritmos é } \\
\text { prescrita para resolução de } \\
\text { situações passo a passo, } \\
\text { remetendo-se a um um } \\
\text { engessamento por meio de uma } \\
\text { resolução linear em detrimento } \\
\text { de apropriações conceituais. }\end{array}$ & $\begin{array}{l}\text { Recomenmda as TD para } \\
\text { o trabalho com } \\
\text { Geometria Espacial, } \\
\text { trazendo a calculadora } \\
\text { para a exploração de } \\
\text { propriedades de figuras } \\
\text { planas e de sólidos. }\end{array}$ \\
\hline $7 .^{\circ}$ & Geometria & $\begin{array}{l}\text { Sugerem a tilização de } \\
\text { software de geometria } \\
\text { dinâmica para atividades de } \\
\text { construções, representações e } \\
\text { verificação de relações. }\end{array}$ & 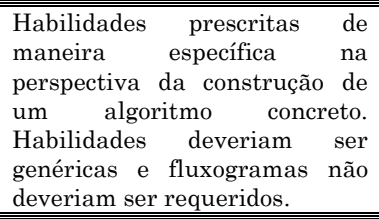 & \\
\hline \multirow{3}{*}{$8 .^{\circ}$} & Números & $\begin{array}{l}\text { Prescrevem a recorrência para } \\
\text { o trabalho com as TD com } \\
\text { números racionais } \\
\text { porcentagens. }\end{array}$ & $\begin{array}{l}\text { Prioriza o desencolvinmento de } \\
\text { habilidades para resolução e } \\
\text { elaboração problemas incluindo } \\
\text { as TD. }\end{array}$ & $\begin{array}{l}\text { Sugerem a Resolução de } \\
\text { problemas e } \\
\text { plausibilidade verificar } \\
\text { resultados por meio de } \\
\text { TD. }\end{array}$ \\
\hline & Geometria & $\begin{array}{ll}\text { Preveêm estudos das } \\
\text { isometrias em processos } \\
\text { recorram às TD. }\end{array}$ & $\begin{array}{l}\text { Ênfase na utilização de } \\
\text { instrumentos de desenho ou } \\
\text { software de geometria } \\
\text { dinâmica. Questiona-se a } \\
\text { concretude do algoritmo, a } \\
\text { especificidade do fluxograma e } \\
\text { as habilidades deveriam ser } \\
\text { genéricas. }\end{array}$ & $\begin{array}{l}\text { Recomendam utilizar TD } \\
\text { em contextos variados e } \\
\text { para previsão e descrição } \\
\text { de soluções, no entanto } \\
\text { sem uma definição clara } \\
\text { dos seus objetivos. }\end{array}$ \\
\hline & Álgebra & $\begin{array}{l}\text { Recomendam a utilização de } \\
\text { TD na resolução de problemas } \\
\text { e em situações que envolvam o } \\
\text { conceito de equações. }\end{array}$ & $\begin{array}{l}\text { Prevê que os alunos deverão } \\
\text { resolver e elaborar problemas } \\
\text { com e sem o uso do recurso das } \\
\text { TD e utilização de fluxogramas. }\end{array}$ & $\begin{array}{l}\text { Referem-se resolução de } \\
\text { problemas em variados } \\
\text { contextos, concebendo e } \\
\text { aplicando estratégias por }\end{array}$ \\
\hline
\end{tabular}




\begin{tabular}{|c|c|c|c|c|}
\hline & & & $\begin{array}{l}\text { Apresenta equívoco } \\
\text { recomendação sobre construir } \\
\text { um algoritmo para determinar o } \\
\text { próximo número de uma } \\
\text { sequência não recursiva, que } \\
\text { não apresenta uma lei de } \\
\text { formação. }\end{array}$ & $\begin{array}{l}\text { meio de TD, porém sem } \\
\text { uma clara definição das } \\
\text { perspectivas desse uso. }\end{array}$ \\
\hline \multirow[b]{2}{*}{$9^{\circ}$} & Números & $\begin{array}{l}\text { Sugerem apropriação das TD } \\
\text { para o trabalho na unidade } \\
\text { Números. }\end{array}$ & $\begin{array}{l}\text { Recomenda a utilização de TD, } \\
\text { preferencialmente } \\
\text { problemas com percentuais } \\
\text { sucessivos. }\end{array}$ & \begin{tabular}{l}
\multicolumn{2}{l}{ Recomenda estratégias } \\
de resolução com \\
problemas envolvendo \\
números reais por meio \\
de TD e calculadora.
\end{tabular} \\
\hline & Geometria & $\begin{array}{l}\text { Indicam recursão às TD com } \\
\text { vistas ao desenvolvimento de } \\
\text { capacidades, habilidades e } \\
\text { competências relativas à } \\
\text { Geometria. }\end{array}$ & $\begin{array}{l}\text { Prescreve o uso de TD } \\
\text { resolução de pa } \\
\text { Geometria, descrição }\end{array}$ & $\begin{array}{l}\text { Indica a esolução } \\
\text { problemas geométricos, } \\
\text { utilizando modelos com } \\
\text { instrumentos variados } \\
\text { que incluem as TD. }\end{array}$ \\
\hline
\end{tabular}

Fonte: Os autores.

Para o 6..$^{\circ}$ ano, na categoria C1, "Alfabetização em TIC/LD", de acordo com os critérios apresentados no Projeto Matemática 2030 (OCDE, 2018), as comparações dos documentos permitiram constatar, em termos de similaridades, que as AE e a BNCC preveem o trabalho com Geometria Plana utilizando TIC como TD. Isso pode ser feito por meio de aplicações interativas, via software específicos para interações digitais, que permitam fornecer, criar e comunicar informações e conceitos.

Especificamente, a BNCC prescreve a construção de figuras semelhantes e planas em situações de ampliação, redução e a construção de retas paralelas e perpendiculares por meio de software específicos, pressupondo componentes que envolvem TD e que os alunos sejam capazes de comunicarem as suas construções. As AE sugerem TD para o trabalho com Geometria Espacial no 6. ${ }^{\circ}$ ano visando a exploração e a comunicação de propriedades de figuras planas e de sólidos.

Para o 7. ${ }^{\circ}$ ano, na categoria $\mathrm{C} 1$, as comparações na unidade "Geometria" evidenciaram que a BNCC e as AE sugerem que recorreram a software para tarefas de construções geométricas, representações e verificação de relações em variados contextos.

Para o 8. $^{\circ}$, categoria $\mathrm{C} 1$, as comparações nas unidades "Geometria", "Números" e "Álgebra" permitiram constatar similaridades ao recomendarem que os alunos sejam alfabetizados para utilização de equipamentos digitais que permitam resolver problemas com conceitos de números racionais e 
porcentagens, isometrias e problemas com equações e comunicar suas soluções. As AE demonstram dificuldades na definição dos propósitos relativos ao uso das TD (GTM, Portugal, 2019).

Para a categoria C2, "Pensamento computacional/programação/ codificação", no 8. $^{\circ}$ ano ficou evidenciado especificamente na BNCC, que os alunos deverão resolver e elaborar problemas com e sem o uso do recurso de TD. A intencionalidade pressupõe implicitamente que possam ser desenvolvidas habilidades ligadas ao PC na formulação de problemas e desenvolvimento de soluções realizadas por TD (OCDE, 2018).

Para o 9. ${ }^{\circ}$ ano, categoria $\mathrm{C} 1$, as comparações nas unidades "Geometria" e "Números" permitiram constatar que alunos devem apropriar-se das TD para resolução de problemas, o que implica a compreensão e habilidade de usabilidade para as construções.

$\mathrm{Na}$ categoria $\mathrm{C} 2$, para o $9^{\circ}$ ano, a $\mathrm{BNCC}$ apresenta especificidades ao pressupor o desenvolvimento de habilidades relativas à resolução de problemas, descrição por extenso e a estruturação de fluxogramas (linguagem considerada ultrapassada) com software de geometria dinâmica.

Prospectivamente infere-se as tendências evidenciadas nas análises dos documentos prescritos dos dois países, no que concerne a categoria $\mathrm{C} 1$, é que os alunos realizem aplicações interativas, se comuniquem digitalmente, realizem tarefas de construções, representações e verifiquem relações.

$\mathrm{Na}$ categoria $\mathrm{C} 2$ a tendência expressa na análise da BNCC é a perspectiva de construção de algoritmos e a utilização de fluxogramas de forma limitada. O documento português não traz nenhuma recomendação clara acerca do desenvolvimento do PC nos anos investigados.

\section{Considerações Finais}

O estudo comparativo evidenciou mais similaridades que especificidades no que tange às prescrições de Brasil e Portugal acerca de recomendações sobre TD na Educação Matemática, indicando convergências nas reformas recentes dos currículos (ICMI Study, 2017). 
A unidade "Números", para o 7. ano, apresentou somente similaridades. As AE (2018) (3. ${ }^{\circ}$ ciclo) e a BNCC (2017) prescrevem que se criem condições para a alfabetização em TIC, indo ao encontro da perspectiva do Projeto Matemática 2030 (OCDE, 2018), configurando-se uma tendência nas prescrições dos dois países.

$\mathrm{Na}$ fase prospectiva, foram inferidas tendências em Educação Matemática nas categorias analíticas para as TD propostas pelo quadro do Projeto Matemática 2030 da OCDE. A análise das habilidades referente à C1 (Alfabetização em TIC/LD), com respeito às similaridades, permitiram inferir que recomendam que os alunos utilizem: aplicações interativas com software específicos para exploração e comunicação digital; software de geometria dinâmica para tarefas de construções geométricas e outros para construção do conceito de números racionais, porcentagens e problemas com equações para representação e verificação de relações em contextos variados.

$\mathrm{Na}$ C2 (PC/Programação/Codificação), as prescrições dos países permitem inferir que deveriam ser repensadas e inseridas em reformas de programas futuros. Em todas as séries dos Anos Finais do Ensino Fundamental, há críticas à construção de algoritmos, utilização de fluxogramas e à prescrição das habilidades muito específicas na BNCC.

Como contributo, a comparação permitiu evidenciar que os documentos prescritos dos países revelaram ênfase na $\mathrm{LD}$ e especificamente a BNCC, poucos e limitados enfoques sobre PC. As AE não apresentam explicitamente nenhuma perspectiva nessa direção. Assim o PC, configura-se em uma perspectiva que demanda maior atenção de pesquisas sobre passagens de domínios matemático e computacional (Barcelos, Munõz, Villarroel e Silveira, 2015; Silveira e Barcelos, 2012) para que seja considerada sem precipitações pelos autores dos programas desses e de outros países. Os objetivos devem ser o desenvolvimento do PC e sua compreensão como habilidade fundamental de linguagem (Wing, 2006), visando a criação de sistemas computacionais necessários para as futuras gerações (PISA, 2016; CSTA, 2011). 
NOTA: O texto é uma das produções do estágio Pós Doutoral realizado pelo primeiro autor no Programa de Pós-Graduação em Educação da Universidade Federal da Bahia (UFBA) e no Programa de Pós-Graduação em Educação, especialidade em Didática da Matemática, do Instituto de Educação (IE) da Universidade de Lisboa (UL), com apoio da Capes.

\section{Referências}

BARCELOS, Thiago Schumacher; SILVEIRA, Ismar Frango. Pensamento Computacional e Educação Matemática: Relações para o Ensino de Computação na Educação Básica. Anais do XXXII Congresso da Sociedade Brasileira de Computação. Anais do CSBC 2012. Curitiba: SBC, julho, 2012.

BARCELOS, Thiago; MUÑOZ, Roberto; VILLARROEL, Rodolfo; SILVEIRA, Ismar Frango. Relações entre o Pensamento Computacional e a Matemática: uma Revisão Sistemática da Literatura. I.F. Anais dos Workshops do IV Congresso Brasileiro de Informática na Educação. CBIE, outubro, 2015.

BEZERRA, Luis Naito Mendes; SILVEIRA, Ismar Frango. Licenciatura em Computação no Estado de São Paulo: uma Análise Contextualizada e um Estudo de Caso. XIX Workshop sobre o Ensino de Computação. Anais do CSBC 2011. Natal: SBC, julho, 2011.

BRASIL. Ministério da Educação LDB - Leis de Diretrizes e Bases. Lei nº 9.394, 1996.

BRASIL. Ministério da Educação. Base Nacional Comum Curricular (BNCC). Ensino Fundamental, 2017.

DICK, Thomas P.; HOLLEBRANS, Karen F. Focus in high school mathematics: Technology to support reasoning and sense making. Reston, VA: NCTM, 2011.

FERRER, Julia. La Educación Comparada actual. Barcelona, Ed. Ariel, 2002.

GTM. Recomendações para a melhoria das aprendizagens dos alunos em Matemática Grupo de Trabalho de Matemática [Despacho.$^{\circ}{ }^{12530 / 2018]}$ - $1^{\mathrm{a}}$ versão - 30 de junho de 2019. Lisboa: Ministério da Educação e Ciência, 2019.

International Commission on Mathematical Instruction. ICMI STUDY 24. School Mathematics Curriculum Reforms: Challegens, Changes and Opportunities. Discussion Document, Tsukuba, Japan, december, 2017.

Computer Science Teachers Association (CSTA). Computational thinking: leadership toolkit. First Edition, 2011.

JENKINS, Henry; PURUSOTMA, Ravi; WEIGEL, Margaret; CLINTON, Katie; ROBISON, Alice J. Confronting the challenges of participatory culture: Media education for the 21st century. Cambridge, MA: MIT Press, 2009.

MARTIN, Allan. A European Framework for Digital Literacy. Nordic Journal of Digital Literacy, v. 2, n. 1, p. 151-161, 2006. 
Organização para a Cooperação e Desenvolvimento Econômico. OCDE. Projeto Matemática 2030. Versão preliminar, Paris, França, 2018.

Organização para a Cooperação e Desenvolvimento Econômico. The Future of Education and Skills Education 2030. Paris, França, 2018. Disponível em: $<$ https://www.oecd.org/education/2030/E2030\%20Position\%20Paper\%20(05.04.201). pdf $>$ Acesso em 20 out. 2018.

PISA. Mathematics in 2021. Analysis of the Center for Curriculum Redesign (CCR). Jan., 2016. Disponível em: <https://curriculumredesign.org/wpcontent/uploads/Recommendations-for-PISA-Maths-2021-FINAL-EXTENDEDVERSION-WITH-EXAMPLES-CCR.pdf>. Acesso em 02 nov. 2018.

PORTUGAL. Lei $\mathrm{n}^{\circ}$ 85/2009. . Lei de Bases do Sistema Educativo. Diário da República, Lisboa, 1. ${ }^{a}$ série, $n^{\circ}$ 166, 27 de Agosto, 2009.

PORTUGAL. Decreto-Lei n ${ }^{\circ} 55 / 2018$. Autonomia e Flexibilização Curricular. Diário da República. Lisboa, 1. ${ }^{a}$ série, $n^{\circ} 129,6$ de julho, 2018. p. 2928-2943.

PORTUGAL. Metas Curriculares de Matemática do Ensino Básico. Lisboa: Ministério da Educação e Ciência, 2012.

PORTUGAL. Programa e Metas Curriculares de Matemática do Ensino Básico. Lisboa: Ministério da Educação e Ciência, 2013.

PORTUGAL. Orientações de Gestão Curricular para o Programa e Metas Curriculares de Matemática para o Ensino Básico. Lisboa: Ministério da Educação e Ciência, 2016.

PORTUGAL. Aprendizagens Essenciais/Articulação com o Perfil do aluno. Matemática. Lisboa: Ministério da Educação e Ciência, julho, 2018.

SACRISTÁN, J. Gimeno. O Currículo: uma reflexão sobre a prática. Porto Alegre: Artmed, 2000.

SHARMA, Sashi. Qualitative approaches in mathematics education research: challenges and possible solutions. Education Journal, v. 2, n. 2, p. 50-57, march 10, 2013.

Sociedade Brasileira de Computação (SBC). Nota Técnica da Sociedade Brasileira de Computação sobre a BNCC-EF e a BNCC-EM. 2018. Disponível em: $<$ http://www.sbc.org.br/institucional-3/cartas-abertas/category/93-cartas-abertas > Acesso em: 20 abr. 2019.

WING, Jeannette. Computational thinking. Communications of the ACM, v.49, n.3, p. 33-35, March, 2006. 